\begin{tabular}{llll}
\hline Submission: 06/09/2020; & $1^{\text {st }}$ round notif.: 18/11/2020; & New version: 17/12/2020; & $2^{\text {nd }}$ round notif.: 09/01/2021; \\
Camera ready: 24/01/2021; & Edition review: 01/02/2021; & Available online: 07/02/2021; & Published: 07/02/2021;
\end{tabular}

\title{
Formação continuada de professores para uso de Tecnologias da Informação e Comunicação (TIC) no Brasil
}

\author{
Continuing teacher education for usage of Information and Communication Technologies \\ (ICT) in Brazil
}

\author{
Milena Jansen Cutrim Cardoso \\ Instituto Federal de Educação, Ciência \\ e Tecnologia do Maranhão (IFMA), \\ Campus São Luís Centro Histórico \\ milena.cardoso@ifma.edu.br
}

\author{
Gil Derlan Silva Almeida \\ Instituto Federal de Educação, \\ Ciência e Tecnologia do Maranhão \\ (IFMA), Campus Bacabal \\ gil.almeida@ifma.edu.br
}

\author{
Thiago Coelho Silveira \\ Instituto Federal de Educação, \\ Ciência e Tecnologia do \\ Maranhão (IFMA), Campus \\ Presidente Dutra \\ silveiratc@hotmail.com
}

\begin{abstract}
Resumo
O presente trabalho analisa ações de formação continuada docente no Brasil que visam promover o uso pedagógico de TIC por professores. Para isso, foi realizada uma Revisão Sistemática de Literatura, com base em publicações filtradas no SciELO, Portal Periódicos da CAPES e Google Acadêmico. Foram identificados 32 artigos dentro da temática, o mais antigo publicado em 2006 e os mais novo em 2018, que revelaram que a maioria das ações utilizaram-se de elementos do ensino a distância e centraram-se em professores de matemática da educação básica pública. A análise dos resultados de formação indicou que as ações contribuíram para o estabelecimento de redes de relacionamento entre os docentes; a construção de conhecimentos e a revelação de significados sobre as TIC; bem como o uso, reflexão sobre a utilização e desenvolvimento de interesse na utilização das TIC, além da formação de conhecimentos disciplinares e a aprendizagem dos alunos.
\end{abstract}

Palavras-Chave: TIC; formação continuada docente; Revisão Sistemática de Literatura.

\begin{abstract}
This paper aims to analyze continuing teacher education actions in Brazil that aim to promote the pedagogical use of ICT by teachers. For this, a Systematic Literature Review was performed, based on publications filtered by SciELO, CAPES Periodical Portal and Google Scholar. Thirty-two articles were identified within the theme, the oldest published in 2006 and the newest in 2018, which revealed that the most training actions used elements of distance learning and focused on mathematics teachers from public basic education. The analysis of the training results indicated that the actions contributed to the establishment of relationship networks between teachers; building knowledge and revealing meanings about ICT; besides the use, reflection about this usage and development of interest in the use of ICT; the formation of disciplinary knowledge; and student's learning.
\end{abstract}

Keywords: ICT; continuing teacher education; Systematic Literature Review.

Cite as: Cardoso, M. J. C., Almeida, G. D. S., \& Silveira, T. C. (2021). Continuing teacher education for usage of Information and Communication Technologies (ICT) in Brazil (Formação continuada de professores para uso de Tecnologias da Informação e Comunicação (TIC) no Brasil). Brazilian Journal of Computers in Education (Revista Brasileira de Informática na Educação - RBIE), 29, 97-116. DOI: 10.5753/RBIE.2021.29.0.97 


\section{Introdução}

A denominação Tecnologias da Informação e Comunicação (TIC) é utilizada para expressar a convergência entre informática e telecomunicações, abrangendo o conjunto de recursos tecnológicos que propiciam agilidade nos processos de comunicação, transmissão e distribuição de informações (Dorneles, 2012; Gewehr, 2016). Pelas TIC permitirem grande volume de armazenamento e transporte de informações, estas tecnologias quebram barreiras de tempo e espaço e conectam pessoas, fatos e conhecimentos de forma global e instantânea (Dorigoni \& Silva, 2013). Por isso, têm transformado de maneira radical e irreversível o modo como os indivíduos trabalham, interagem, aprendem e ocupam os seus tempos livres (Pedro \& Piedade, 2013).

Considerando o cenário de mudanças provenientes das transformações tecnológicas, a educação formal deve se comprometer com o desenvolvimento de cidadãos que saibam lidar com as TIC, auxiliando no processo de inclusão digital (Oliveira \& Lima, 2015). De acordo com Silva, Jambeiro, Lima e Brandão (2005), a inclusão digital tem como ponto central a educação para a informação. Assim, incluir digitalmente os estudantes não significa apenas apresentá-los aos recursos tecnológicos e ensiná-los habilidades básicas para o uso de computadores e da Internet, mas auxiliá-los na construção de conhecimentos para utilização dessas mídias a favor dos interesses e necessidades individuais e comunitários, com responsabilidade e senso de cidadania (Takahashi, 2000).

Desta maneira, a inserção de atividades e práticas pedagógicas que contemplem o uso das TIC tornam-se importantes aliados num processo de ressignificação do ensino-aprendizagem tradicional, pois através dessas mudanças, a construção do conhecimento passa a ganhar um caráter mais reflexivo e consciente. No trabalho com essas tecnologias inseridas no ambiente escolar, o aluno desenvolve autonomia, criticidade e capacidade para ir em busca de suas próprias conquistas. Assim, podemos nos deparar com um sujeito mais independente e dono de si. Aliar a tecnologia, metodologias e práticas em prol da construção de uma educação inovadora seria, de fato, trabalhar uma visão de ensino-aprendizagem com inúmeras possibilidades na produção de saberes.

Documentos curriculares nacionais defendem o uso pedagógico das TIC há pelo menos duas décadas. Os Parâmetros Curriculares Nacionais (Brasil, 1997) estabelecem como um dos objetivos de aprendizagem da educação básica: "saber utilizar diferentes fontes de informação e recursos tecnológicos para adquirir e construir conhecimentos" (p. 69). As Diretrizes Curriculares Nacionais para a Educação Básica (Brasil, 2013) incentivam a presença de infraestrutura tecnológica na escola como apoio pedagógico às atividades escolares, de maneira que os "recursos tecnológicos de informação e comunicação estimulem a criação de novos métodos didáticopedagógicos" (p. 25-26). Mais recentemente, a Base Nacional Comum Curricular (BNCC) ratifica tal importância, ao indicar que a educação deve possibilitar ao estudante:

Compreender, utilizar e criar tecnologias digitais de informação e comunicação de forma crítica, significativa, reflexiva e ética nas diversas práticas sociais (incluindo as escolares) para se comunicar, acessar e disseminar informações, produzir conhecimentos, resolver problemas e exercer protagonismo e autoria na vida pessoal e coletiva. (Brasil, 2018, p. 09).

A importância da inclusão das TIC nos processos de ensino-aprendizagem também é evidenciada nas Diretrizes Curriculares Nacionais para a formação inicial em nível superior e para a formação continuada de Professores (Brasil, 2015). Segundo este documento, o processo de formação profissional deve possibilitar o desenvolvimento de conhecimentos que levem ao uso competente das TIC, de forma que o professor formado possa utilizar as tecnologias educacionais 
e diferentes recursos e estratégias didático-pedagógicas no desenvolvimento, execução, acompanhamento e avaliação de projetos educacionais.

Mais recentemente, as diretrizes para a formação continuada de professores foram atualizadas com a publicação da Resolução CNE/CP N 1.2020 , que instituiu a Base Nacional Comum para a Formação Continuada de Professores da Educação Básica (Brasil, 2020). Na BNCFormação Continuada, como o documento é conhecido, os professores são convidados a cada vez mais inserir o uso das TIC nas suas mais variadas práticas pedagógicas. O documento fomenta que estas inserções tecnológicas propiciam, além do desenvolvimento cognitivo, o crescimento emocional do aluno, pois atuando diretamente em como o aluno apreende os saberes, o professor estaria agindo mais proficuamente nos interesses educativos de seu público. Outro ponto importante que o documento suscita seria a possibilidade do estreitamento na relação escola/comunidade com a inserção das TIC. Tornando, assim, realidade nos contextos escolares, as possibilidades de divulgação do trabalho pedagógico da escola, bem como a comunicação com a sociedade, a fim de um ganho potencial para o cenário escolar que se almeja para o futuro. A troca de experiências, vivências e diversos outros conhecimentos não teria barreiras de alcance com o uso das tecnologias. É importante ressaltar que todas essas observações e indicações lançadas pelo documento oficial lidam diretamente com a formação do professor para o uso dessas tecnologias, elemento primordial de debate dentro dessas novas mudanças que se conjecturam.

A inserção das TIC nas práticas de ensino exige que os professores conheçam o computador, os suportes midiáticos e as possibilidades educacionais e interativas para aproveitá-las nas mais variadas situações de ensino-aprendizagem e nas diferentes realidades educacionais (Kenski, 2001). A responsabilidade docente não se encerra na manipulação do computador ou de um programa específico, mas contempla também conhecimentos sobre como utilizá-los para promover a dinamização das aulas, a construção e difusão de conhecimentos e a promoção da autonomia dos alunos a fim de que as novas tecnologias não fiquem restritas a velhas metodologias (Oliveira \& Lima, 2015; Schuhmacher, Alves-filho, \& Schuhmacher, 2017).

Devido à complexidade de saberes e práticas necessárias ao professor, a introdução das TIC nas práticas pedagógicas tem se mostrado um grande desafio. Pesquisas têm abordado os desafios que docentes de diferentes níveis da educação e de diversas disciplinas enfrentam. Alguns obstáculos estão relacionados à infraestrutura e recursos disponíveis na escola, como a falta de equipamentos, conexão instável de internet, qualidade e adequação dos materiais tecnológicos e recursos humanos para apoio técnico e pedagógico (Casquero, García, \& González, 2011; Peralta \& Costa, 2007). A organização e o currículo escolar também podem impor dificuldades ao uso das TIC, pois os programas escolares costumam ser engessados e não evidenciam a integração das tecnologias com os conteúdos das disciplinas, os materiais curriculares são carentes ou inadequados e os professores têm pouco ou nenhum tempo para o planejamento de suas aulas (Casquero et al., 2011; Peralta \& Costa, 2007; Soares-leite \& Nascimento-Ribeiro, 2012). Além disso, há também obstáculos referentes à formação do professor, que muitas vezes não vivenciaram o uso das TIC nos seus cursos de formação e estágios, o que impede o desenvolvimento de conhecimentos relacionadas à capacidade de integrar as TIC ao processo de ensino (Bingimlas, 2009; Peralta \& Costa, 2007; Silva, Prates, \& Ribeiro, 2016).

As barreiras relacionadas à formação têm sido apontadas como as mais relevantes, uma vez que os professores atribuem grande importância à formação como forma de desenvolver a sua confiança e atitude positiva para o uso das TIC em contexto escolar (Peralta \& Costa, 2007; Soares-Leite \& Nascimento-Ribeiro, 2012). Diante disso, as instituições formadoras de professores devem possibilitar aos docentes a utilização de ferramentas tecnológicas a favor dos processos de ensino-aprendizagem (Dorneles, 2012).

Estudos têm apresentado a fragilidade da inserção curricular das TIC nos cursos de licenciatura, uma vez que os seus projetos de curso, matrizes curriculares e disciplinas de práticas 
de ensino não têm considerado temas que envolvam as tecnologias ou o fazem de maneira incipiente (Dorneles, 2012; Estevam \& Sales, 2018; Schuhmacher et al., 2017). Em contrapartida, a oferta de formação continuada tem sido considerada em diferentes políticas públicas (Dorneles, 2012). Alguns exemplos de programas em âmbito federal que apresentam como um dos focos a formação continuada de professores para a inserção das TIC em suas práticas pedagógicas são o Projeto FORMAR, lançado no fim da década de 1980; o ProInfo (Programa Nacional de Informática na Educação), lançado em 1997 e reestruturado em 2007 com o nome de ProInfo Integrado (Programa Nacional de Tecnologia Educacional); o Mídias na Educação, criado em 2005; e o ProUCA (Programa Um Computador por Aluno), instituído em 2007 (Almeida \& Valente, 2016; Souza \& Schneider, 2016). Além disso, ações de formação continuada também têm sido promovidas pelas gestões das redes estadual e municipal de ensino, bem como pela iniciativa privada (Davis, Nunes, Almeida, Silva, \& Souza, 2012).

A oferta de formação continuada docente no Brasil que visa aproximar os professores às TIC suscita as questões: quais as características dessas ações de formação e como elas têm contribuído para o desenvolvimento profissional docente dos professores que participam delas? Assim, essa pesquisa objetiva construir um panorama acerca das ações de formação continuada docente no Brasil que promovem o uso pedagógico das TIC por professores a partir de uma Revisão Sistemática de Literatura (RSL). Algumas RSL já propuseram a investigação da formação de professores para o uso pedagógico de tecnologias digitais no contexto brasileiro, mas o fizeram a partir de perspectivas mais restritas, como o foco em professores de determinadas áreas de conhecimento (e.g. Atanazio, \& Leite, 2018; Oliveira, Delamuta, Silveira, \& Mól, 2018); a partir de referenciais teóricos específicos, como letramento digital (e.g.: Costa \& Ferreira, 2020; Moura, 2019) e TPACK $^{1}$ (Nogueira, Pessoa \& Gallego, 2015); ou em contexto de publicação mais localizados, como em trabalhos publicados nas reuniões da Associação Nacional de PósGraduação e Pesquisa em Educação - ANPED (Spagnolo, Mantovani, Santos, \& Müller, 2014). Dessa forma, a construção do panorama aqui proposto visa contribuir com as investigações já realizadas, ampliando o mapeamento do cenário brasileiro sobre a temática.

\section{Metodologia}

Este estudo é uma Revisão Sistemática de Literatura (RSL), tipo de pesquisa que utiliza como fonte de dados a literatura sobre determinado tema, possibilitando uma investigação que visa identificar evidências relacionadas a um problema específico de pesquisa (Gonçalves, Nascimento, \& Nascimento, 2015). O protocolo de execução desta RSL teve os seguintes elementos: definição da pergunta da revisão, estabelecimento de critérios de inclusão, delimitação das estratégias de busca de pesquisas, avaliação crítica dos estudos e coleta e síntese dos dados (Galvão, Sawada, \& Trevizan, 2004). Cada elemento é descrito a seguir.

A pergunta de pesquisa que orientou a realização desta RSL foi: quais as características dessas ações de formação, e ainda, elas têm contribuído para o desenvolvimento profissional docente dos professores que participam delas? Para responder à questão, definiu-se que os estudos incluídos nesta RSL deveriam ser artigos empíricos, publicados em periódicos, que analisassem ações concretas de formação continuada de professores para o uso pedagógico das TIC.

De posse da pergunta e dos critérios de inclusão, procedeu-se com a busca dos estudos, elemento relacionado à identificação das publicações relevantes ao contexto investigado. Considerando que o foco de investigação recai na associação entre formação continuada de professores e utilização das TIC nos processos de ensino-aprendizagem, os seguintes indexadores foram usados: "formação continuada de professores", "formação continuada docente", "formação

\footnotetext{
${ }^{1}$ TPACK é a sigla em inglês para Conhecimento Tecnológico Pedagógico do Conteúdo.
} 
de professores" e "formação docente", relacionados ao primeiro tema, e "tecnologia educativa", "informática educativa", "TIC", "Tecnologias da Informação e Comunicação", "TDIC", "Tecnologias Digitais da Informação e Comunicação", "novas tecnologias", "tecnologias digitais e analógicas" e "ambientes virtuais", termos notadamente recorrentes na área de tecnologia educacional (Mill, 2013). Os operadores lógicos and e or foram usados para combinar os indexadores. A formatação dos indexadores e operadores lógicos obedeceu às regras de cada repositório consultado, que foram: The Scientific Electronic Library Online (SciELO), Portal Periódicos da CAPES e Google Acadêmico, escolhidos pela sua relevância no contexto nacional para a área da educação e por permitir acesso a trabalhos de diferentes periódicos. Definiu-se o ano de 2019 como limite superior para a busca de artigos em relação ao período de publicação. A quantidade de trabalhos encontrados em cada repositório é detalhada na tabela 1.

Tabela 1: Quantidade de publicações filtradas pelos repositórios.

\begin{tabular}{|c|c|}
\hline Repositório & Publicações filtradas \\
\hline CAPES & 523 \\
\hline SciELO & 133 \\
\hline Google Acadêmico & $100 *^{*}$ \\
\hline Total & 1656 \\
\hline
\end{tabular}

*O Google Acadêmico encontrou 16500 resultados, mas só permitiu acesso aos 1000 primeiros.

Ainda dentro do processo de busca, foi realizada a triagem do material identificado com base nos critérios de inclusão definidos no início da pesquisa. Esse processo ocorreu em três etapas. Na primeira, observou-se de maneira geral as publicações obtidas, com o intuito de excluir as que não correspondiam a artigos científicos publicados em periódicos, que não disponibilizavam o texto completo, além das duplicadas. A segunda etapa correspondeu à leitura do título, resumo e palavras-chaves para eliminar os artigos não relacionados à formação continuada docente e TIC, não empíricos (teóricos, estados da arte e revisões sistemáticas de literatura ou narrativas) e os não realizados em território nacional. Por fim, a última etapa consistiu na leitura completa dos artigos para excluir os que não apresentavam resultados de formação referentes aos professores participantes das ações. Após o cumprimento das três etapas de exclusão, as 1656 publicações filtradas pelos repositórios foram reduzidas a 45 artigos (figura 1).

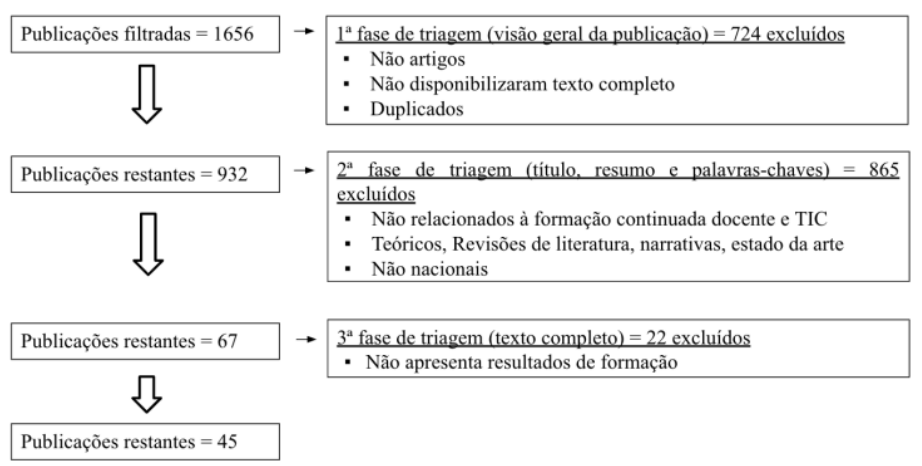

Figura 1: Triagem das publicações encontradas

As 45 publicações restantes passaram por uma avaliação crítica, com o intuito de observar a credibilidade e relevância do artigo. Primeiramente, foram consultados os Qualis dos periódicos, tendo sido mantidos os trabalhos publicados em revistas com Qualis superior a B3 ${ }^{2}$ para as áreas

\footnotetext{
${ }^{2}$ As revistas com Qualis de A1 a B2 têm fator de impacto medido pelo Institute for Scientific Information (ISI), o que não ocorre com as de Qualis igual ou menor que B3.
} 
de Educação e Ensino. Os artigos mantidos foram analisados através do CASP Qualitative Studies Checklist (Critical Appraisal Skills Programme - CASP, 2018), um checklist que auxilia na análise metódica de possíveis vieses em publicações de cunho qualitativo ${ }^{3}$. No presente trabalho foram considerados todos os artigos que apresentavam viés de risco menor (artigos que preencheram pelo menos nove dos 10 itens do checklist) e moderado (artigos que preencheram pelo menos cinco dos 10 itens do checklist). O processo de avaliação crítica filtrou 32 artigos, que compuseram o corpus desta pesquisa e que são apresentados no Apêndice.

Com o corpus de pesquisa definido, ocorreu a coleta de dados a partir da extração e organização em planilha de informações relacionadas a quatro itens (figura 2): o artigo, as características da ação de formação, a identificação dos participantes e os resultados de formação. Os dados relacionados aos três primeiros itens foram extraídos diretamente das publicações. Já em relação aos resultados de formação, foi realizada Análise de Conteúdo (Bardin, 2016) nas sessões referentes a resultados e discussão dos artigos, com o intuito de identificar as principais temáticas abordadas e construir categorias que reunissem os elementos semelhantes.

\begin{tabular}{|c|}
\hline $\begin{array}{c}\text { Informações } \\
\text { artigo }\end{array}$ \\
\hline Autores \\
\hline $\begin{array}{c}\text { Ano de } \\
\text { publicação }\end{array}$ \\
\hline Título \\
\hline $\begin{array}{c}\text { Objetivos e/ou } \\
\text { Pergunta de } \\
\text { pesquisa }\end{array}$ \\
\hline
\end{tabular}
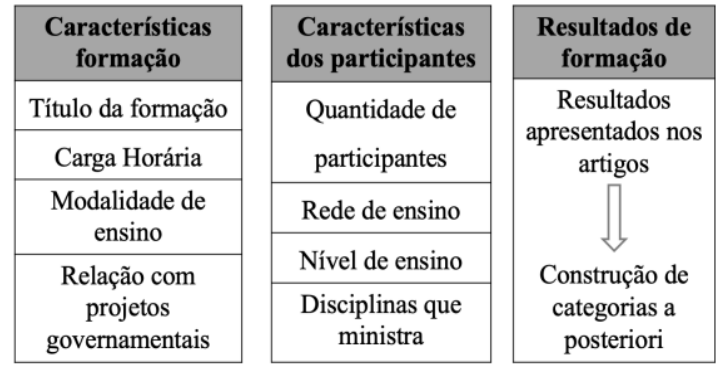

Figura 2: Informações extraídas dos artigos

\section{Resultados e discussão}

\subsection{Artigos}

A relação dos 32 artigos que compõem o corpus dessa RSL é apresentada no apêndice e o intervalo de publicação dos trabalhos encontrados foi de 2006 (A25) a 2018 (A9 e A23) (figura 3).

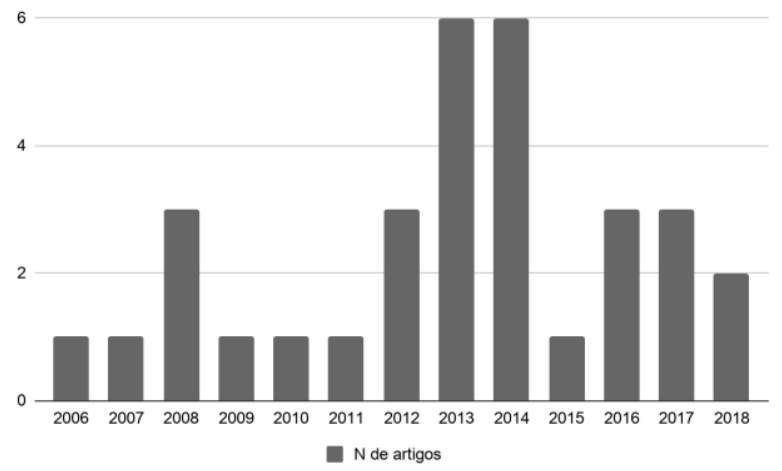

Figura 3: Ano de publicação dos artigos

\footnotetext{
${ }^{3}$ Itens avaliados pelo checklist do CASP: 1 . objetivo claro e justificado; 2 . desenho metodológico apropriado aos objetivos; 3. procedimentos metodológicos apresentados e discutidos; 4. seleção da amostra intencional; 5. coleta de dados descrita, instrumentos explicitados e processo de saturação; 6. relação entre pesquisador e pesquisado; 7. cuidados éticos; 8. análise densa e fundamentada; 9. resultados apresentados e discutidos, apontando o aspecto da credibilidade e uso da triangulação; 10. descrição sobre as contribuições e implicações do conhecimento gerado pela pesquisa, bem como, suas limitações.
} 
Esses dados indicam que a publicação de pesquisas sobre a formação continuada de professores para uso pedagógico das TIC não acompanhou os primeiros movimentos em âmbito nacional voltados para a implantação da informática na educação, iniciados nos anos $80 \mathrm{com}$ a realização de Seminários Nacionais de Informática em Educação e com o lançamento do projeto EDUCOM (Almeida, \& Valente, 2016). Como afirmam esses autores, apesar de aspectos formativos constarem nos pressupostos de diferentes projetos nacionais que visavam a introdução de recursos tecnológicos nas escolas brasileiras, a primeira iniciativa pública no país que impulsionou a integração entre a tecnologia e as atividades curriculares em situações autênticas de sala de aula foi viabilizada pelo ProUCA, programa iniciado em 2007. Assim, a carência de pesquisas sobre formação de professores para uso das TIC antes dos anos 2000 pode estar vinculada à falta de ações formativas mais concretas na área. Uma vez que os principais investigadores sobre formação de professores estavam focados nos cursos de licenciatura nos anos 80 e 90 (Romanowski, 2013), também é pertinente supor que a atenção sobre a formação continuada seja, de fato, mais recente. Ainda é possível considerar que as escolhas metodológicas definidas nesta RSL, notadamente a de utilizar somente artigos publicados em periódicos e desconsiderar outros tipos de publicação (dissertações, teses, trabalhos apresentando em eventos e outros), pode ter contribuído para esse resultado

\subsection{Ações de formação}

Foram apresentadas 28 ações de formação nos 32 artigos analisados. A quantidade de ações foi menor do que a de artigos, pois algumas formações foram objeto de estudo de mais de uma publicação. Isso ocorreu com a "Oficina sobre a metodologia WebQuest para o ensino da matemática", analisada em A2 e A3, e com a "T-PROIM" (Tecnologias na Prática docente de pROfessores Iniciantes de Matemática), ação pesquisada em A4, A5, A6 e A7.

Em 18 ações de formação, não foi possível identificar a carga horária total de atividades. Dentre as que apresentaram essa informação, a carga horária variou de 16 horas, da "Oficina de utilização de Geogebra" apresentada em A1, e 480 horas, do "Curso de Especialização em Educação em Ciências e Tecnologia" descrito em A27. Esses dados estão de acordo com a heterogeneidade na oferta de formação continuada evidenciada por Gatti (2008), que indica que um dos únicos pontos de convergência entre essas iniciativas é o fato delas serem oferecidas em formatos que não exigem credenciamento ou reconhecimento institucional, uma vez que costumam ocorrer no âmbito da extensão universitária ou da pós-graduação latu-sensu.

Em relação à modalidade (Tabela 2), 36\% das ações de formação descritas foram semipresenciais, modalidade em que parte das atividades ocorre de maneira presencial e parte acontece a distância. As ações ministradas totalmente a distância e totalmente presencial representaram $32 \%$ e $21 \%$ do total, respectivamente. Esses resultados evidenciam a tendência de oferta de cursos que apresentem algum componente a distância, observada na promoção da formação inicial e continuada de professores (Bahia, 2014; Barreto, Guimarães, Magalhães, \& Leher, 2006). A educação a distância (EaD) engloba todos os processos de ensino-aprendizagem mediatizados que apresentam um compromisso de acompanhamento e seguimento pedagógicos (Mamede-Neves, 1996). No contexto da formação continuada, entende-se que se bem direcionada e com o apoio dos recursos adequados, a EaD pode ser um meio eficiente de mobilização de estratégias que viabilizem os princípios e fins da educação permanente, por ela proporcionar o rompimento das barreiras de acesso à educação (Pedrosa, 2003). 
Tabela 2: Modalidades das ações de formação

\begin{tabular}{|c|c|}
\hline Modalidades das ações de formação & $\%$ \\
\hline Semipresencial & $36 \%$ \\
\hline A distância & $32 \%$ \\
\hline Presencial & $21 \%$ \\
\hline Não aborda & $11 \%$ \\
\hline
\end{tabular}

Assim, as TIC têm sido não apenas o objeto de estudo das ações de formação, mas também instrumento para a aprendizagem, uma vez que as ações a distância e semipresenciais sempre se utilizam de ambientes virtuais de aprendizagem, redes sociais ou ferramentas de comunicação eletrônicas para disponibilizar materiais, enviar informações e/ou estimular a interação entre cursistas. Esse processo é denominado por Barreto et al. (2006) como "virtualização" do ensino, pois aponta para a ruptura com a demarcação da sala de aula da forma como conhecemos, redimensionando a escala de tempo-espaço das situações de ensino-aprendizagem. Considerando os dados apresentados, vê-se a importância da imersão dos professores em práticas de formação continuada com o uso de tecnologias, uma vez que estas podem auxiliar o trabalho pedagógico desenvolvido no ensino presencial. Mas para tanto, é necessário que o professor domine o uso das ferramentas, a fim de que a sua aplicabilidade possa direcionar ao alcance dos objetivos de aprendizagem traçados.

Vale ressaltar que a pesquisa desenvolvida não abarcou a produção bibliográfica realizada em torno da temática do uso das tecnologias durante a pandemia da Covid-19, considerando que a busca ativa de produções se deu em período anterior à pandemia, mas o cenário permite apontar que a necessidade de formação continuada nessa temática ainda não foi suficientemente sanada. A utilização emergencial de ensino remoto, que não pode se confundir com a modalidade EaD nos termos definidos na legislação vigente e conforme apontado por Faria e Lopes (2013), tem denunciado essa carência, ao passo que também tem reforçado o caráter positivo de práticas pedagógicas inovadoras que ocorrem por meio do de tecnologias.

Das ações pesquisadas, apenas 6 estavam atreladas a projetos governamentais de incentivo ao uso pedagógico das TIC. Em A14 e A24 foi analisado o contexto de formação da "Pósgraduação lato sensu em Mídias na Educação", em A21 foi publicada pesquisa sobre o "ProInfo Integrado" e A19 investigou o "ProUCA". Além de projetos federais, programas estaduais ou municipais também foram analisados, como o "Projeto Eureka", implantado pela prefeitura de Campinas (SP) e descrito em A25, e o "Projeto Escolas em Rede", da rede estadual de Minas Gerais analisado em A30. Esses resultados indicam que os esforços de investigação científica não têm sido focados nas políticas nacionais de formação continuada docente para uso pedagógico das TIC. Tais ações devem ser pesquisadas, já que demandam vasto financiamento público e costumam ocorrer em larga escala, apresentando, portanto, grande potencial de gerar impactos. Como comentam Martins e Flores (2015) sobre o ProInfo, comentário este que pode ser estendido às políticas públicas para a efetivação do uso das tecnologias no espaço escolar no geral, o acompanhamento e avaliação constantes e efetivas por parte do Ministério da Educação certamente daria subsídios para que intervenções pudessem ser realizadas a tempo, otimizando os resultados do programa. 


\subsection{Público participante}

A quantidade de professores envolvidos nas ações de formação variou de dois, em um grupo colaborativo descrito em A13, a 8000 professores, no "Curso de Formação Continuada de Professores em Tecnologias de Informação e Comunicação Acessíveis", ação de formação a distância analisada em A12, e que atendeu a professores da América Latina, América Central e Espanha em 17 edições.

Características dos docentes participantes das formações são detalhadas na tabela 3. A maior parte do público atendido é da rede pública (54\%) e atua na educação básica (18\%). Embora muitos artigos não indicassem explicitamente as redes e o nível de ensino dos docentes participantes, o foco em formação continuada para professores da educação básica pública também foi encontrado em RSL publicadas por Atanazio e Leite (2018) e Spagnolo et al. (2014), o que pode indicar que esse público tem sido privilegiado em formações com a finalidade de promover a incorporação das TIC nas práticas pedagógicas. Professores de todas as redes e níveis de ensino apresentam dificuldades na utilização das novas tecnologias em sala de aula. A situação é ainda mais problemática, contudo, se considerarmos que os professores universitários não costumam possuir formação sólida no campo pedagógico (Pretto, \& Riccio, 2010). Se uma formação geral para o exercício da docência é deficitária, é de se esperar que esses profissionais também não apresentem formação específica para o uso de tecnologias educacionais. Uma implicação desse cenário é que os licenciandos não entram em contato com modelos didáticos que contemplem o uso das TIC, já que eles provavelmente têm pouco ou nenhum contato com recursos tecnológicos em situações de ensino-aprendizagem enquanto estudantes de graduação. Negligenciar, portanto, a formação de docentes da educação superior para o uso pedagógico das TIC cria um efeito cascata em toda a rede educacional.

No que diz respeito às disciplinas ministradas pelos professores participantes das ações de formação (figura 6), a maior parte das ações que identificava esse dado era focada em professores de matemática (29\% do total). Esse público geralmente configura-se como alvo prioritário de ações de desenvolvimento profissional docente (e.g. Davis et al., 2012; Matos, Souza, Nascimento, Pinto, \& Souza, 2016). Isso pode estar atrelado ao histórico de insucesso dos alunos nessa disciplina, o que preocupa os responsáveis pelo processo educativo e os enseja à procura de novos recursos (Martins, 2009). Desde os anos 80 tem havido a disseminação de novos produtos produzidos pela tecnologia para o ensino de matemática, como calculadoras eletrônicas, microcomputadores, robôs programáveis e outros dispositivos, o que provoca transformações nos conteúdos e nas maneiras pelas quais se processam o ensino e a aprendizagem (Miskulin et al., 2006).

Tabela 3: Características dos professores participantes

\begin{tabular}{|l|l|l|}
\hline \multicolumn{2}{|l|}{ Características dos professores participantes } & $\%$ \\
\hline \multirow{2}{*}{$\begin{array}{l}\text { Redes de ensino em que os } \\
\text { professores atuavam }\end{array}$} & Rede pública apenas & $54 \%$ \\
\cline { 2 - 4 } & Rede pública e privada & $3 \%$ \\
\cline { 2 - 4 } & Não aborda & $43 \%$ \\
\hline $\begin{array}{l}\text { Nível de ensino em que os } \\
\text { professores atuavam }\end{array}$ & Educação básica apenas & $18 \%$ \\
\cline { 2 - 4 } & Educação básica e superior & $11 \%$ \\
\cline { 2 - 3 } & Educação superior apenas & $3 \%$ \\
\cline { 2 - 4 } & Não aborda & $68 \%$ \\
\hline
\end{tabular}




\begin{tabular}{|l|l|l|}
\hline $\begin{array}{l}\text { Disciplinas ministradas pelos } \\
\text { professores }\end{array}$ & Matemática & $29 \%$ \\
\cline { 2 - 3 } & Diversas disciplinas & $15 \%$ \\
\cline { 2 - 3 } & Línguas (inglês, espanhol) & $11 \%$ \\
\cline { 2 - 3 } & $\begin{array}{l}\text { Anos iniciais do ensino } \\
\text { fundamental }\end{array}$ & $3 \%$ \\
\cline { 2 - 3 } & Não aborda & $42 \%$ \\
\hline
\end{tabular}

Mais recentemente, a BNCC (Brasil, 2018) apresentou-nos ao uso do pensamento computacional como um recurso para a ampliação das possibilidades de trabalho com diversos conteúdos e saberes da área. Este pensamento, que auxilia na resolução de problemas e questões, pauta-se na assimilação de uma nova linguagem para a comunicação e produção de conhecimento. O uso da tecnologia, estritamente ligada a essa inovação pedagógica, auxilia o docente a fomentar no aluno a tradução das situações-problemas para a linguagem computacional, campo de estudos que merece investigação e se apresenta com inúmeras alternativas benéficas ao processo de ensino-aprendizagem.

Contudo, é importante salientar que professores de outras áreas do conhecimento, como as ciências naturais por exemplo, também relatam dificuldades na utilização de TIC nos processos de ensino-aprendizagem (Schuhmacher et al., 2017). Por isso, ações de formação que se concentrem em diferentes áreas do conhecimento são necessárias e de extrema importância.

\subsection{Resultados de formação}

Os resultados apresentados nos artigos foram reunidos em oito categorias, construídas a partir do material analisado (Tabela 4). As categorias não são mutuamente excludentes, uma vez que alguns artigos apresentaram resultados que destacam diferentes aspectos formativos. Os detalhes das categorias e exemplos serão discutidos a seguir.

$\mathrm{Na}$ categoria Estabelecimento de redes de relacionamento entre os docentes foram reunidos os resultados que discutem se as ações de formação propiciaram um ambiente de interação, compartilhamento de conhecimentos e trabalho colaborativo entre os docentes. Alguns artigos utilizaram referenciais de análise específicos para a avaliação de interações, a exemplo de A6 e A7 que identificaram a presença de Dimensões do Capital Social (DCS) ${ }^{4}$ nas situações de formação ocorridas no curso T-PROIM, e A32, que analisou três edições de um curso de extensão universitária sobre elaboração de materiais para aprendizagem de línguas em meio telemático e encontrou indícios de que o Benefício Recíproco ${ }^{5}$ e a Sustentação Solidária ${ }^{6}$ foram elementos fundamentais para a emergência e sobrevivência do grupo de professores cursistas. O estabelecimento de redes de relacionamento entre docentes cria um ambiente onde os professores podem encontrar suporte nos seus colegas, propiciando o compartilhamento de dificuldades e sucessos e facilitando a superação dos problemas diários (Baptista, 2014).

\footnotetext{
${ }^{4}$ As DCS são definidas como "a capacidade dos indivíduos de acumular benefícios por meio da força dos seus relacionamentos pessoais e da associação em redes e estruturas sociais específicas" (Warschauer, 2006 apud Barcelos, Passerino, \& Behar, 2013).

${ }^{5} \mathrm{O}$ benefício recíproco trata da dupla valorização das ações de um indivíduo para com outro dentro de uma relação interativa (Piaget, 1973 apud Vetromille-Castro, 2008).

${ }^{6}$ A sustentação solidária consiste numa concentração espontânea de esforços de caráter desinteressado em trocas interindividuais que visam dar suporte ao processo de construir e manter uma ordem funcional e estrutural num sistema aberto, durante os sucessivos estados de equilíbrio (Estrázulas, 2004 apud Vetromille-Castro, 2008)
} 
Tabela 4: Resultados abordados nos artigos

\begin{tabular}{|l|c|l|}
\hline \multicolumn{1}{|c|}{ Categoria } & N de artigos & \multicolumn{1}{c|}{ Artigos } \\
\hline $\begin{array}{l}\text { Estabelecimento de redes de relacionamento entre os } \\
\text { docentes }\end{array}$ & 18 & $\begin{array}{l}\text { A2, A4, A6, A7, A9, A11, A13, } \\
\text { A14, A15, A16, A18, A19, A22, } \\
\text { A24, A25, A27, A28, A32 }\end{array}$ \\
\hline Construção de conhecimentos sobre o uso das TIC & 12 & $\begin{array}{l}\text { A1, A2, A3, A6, A7, A8, A15, } \\
\text { A16, A23, A24, A26, A31 }\end{array}$ \\
\hline Uso das TIC na prática docentes & 9 & $\begin{array}{l}\text { A4, A8, A13, A14, A16, A17, } \\
\text { A19, A20, A30 }\end{array}$ \\
\hline Reflexão sobre o uso das TIC & 7 & A2, A8, A9, A13, A25, A27, A28 \\
\hline Significados atribuídos por professores & 3 & A10, A21, A29 \\
\hline Construção de conhecimentos disciplinares & 2 & A12, A23 \\
\hline Aprendizagem dos alunos & 2 & A14, A19 \\
\hline Interesse em utilizar as TIC futuramente & 1 & A2 \\
\hline
\end{tabular}

Embora a maioria dos resultados classificados nessa categoria tenham registrado evidências positivas para o estabelecimento de redes de interação e colaboração, alguns registraram que as ações de formação analisadas propiciaram baixa ou nenhuma interatividade. Isso foi descrito em A9, que descreveu um curso de formação de professores a distância que teve como objetivo possibilitar momentos de reflexão sobre a prática pedagógica com uso de tecnologias digitais na sala de aula.

Alguns resultados de formação focaram na Construção de conhecimentos sobre o uso das TIC, categoria que aborda sobre o aprendizado de conhecimentos que possibilitam a integração de tecnologias ao ensino. Esse tema foi tratado em 12 artigos. Alguns recursos tecnológicos explorados nas ações de formação foram o GeoGebra, um aplicativo que combina conceitos de geometria e álgebra (A1, A15, A23 e A26); o Webquest, ferramenta que permite a organização de atividades de pesquisa com recursos na internet (A2 e A3); o SuperLogo, software que trabalha a linguagem de programação (A31); e o blog, um tipo de site que possibilita a publicação de postagens em ordem cronológica (A5). Para investigar o aprendizado sobre o uso pedagógico de TIC, alguns referenciais de análise utilizados foram a Gênese Instrumental ${ }^{7}$ (A1), o Conhecimento Tecnológico e Pedagógico do Conteúdo (TPACK $)^{8}$ (A15, A26 e A31) e o Letramento Digital ${ }^{9}$ (A7).

Os resultados agrupados na categoria Uso das TIC na prática docente discutem se as ações de formação propiciaram a incorporação dos recursos abordados durante a formação na prática pedagógica dos professores. Algumas das TIC introduzidas nas práticas docentes foram: blogs, vídeos e lousa digital, por professores participantes do curso "Utilização de Objetos de Aprendizagem em Sala de Aula Mediatizado pelas Tecnologias Digitais" (A17); tecnologias assistivas, por docentes que realizaram os cursos "Tecnologia Assistiva, Projetos e

\footnotetext{
${ }^{7}$ A Gênese Instrumental estuda a transformação de um artefato (por exemplo, a tecnologia) em instrumento (os esquemas de utilização do artefato desenvolvidos pelo usuário) (Rabardel, 1995 apud Abar \& Alencar, 2013).

${ }^{8} \mathrm{O}$ TPACK agrega conhecimento dos conteúdos disciplinares, dos métodos pedagógicos e das tecnologias na promoção da utilização das TIC na prática pedagógica (Mishra \& Koehler, 2006 apud Cyrino \& Baldini, 2017).

${ }^{9}$ O Letramento Digital, de acordo com a classificação proposta por Warschauer (2006 apud Barcelos, Passerino, \& Behar, 2013) letramento por meio do computador, letramento informacional, letramento multimídia e letramento comunicacional mediado por computador.
} 
Acessibilidade: Promovendo a Inclusão de Deficientes" (A8) e "Formação em Serviço de Professores em Informática na Educação Especial" (A16); e laptops, por participantes do "Curso de Formação do ProUCA - Tocantins" (A19).

Houve casos, entretanto, que assinalaram a falta de integração das tecnologias à prática docente mesmo após as ações de formação. Em A30 foram analisados professores participantes do Programa FIT (Formação Inicial para o Trabalho) da Secretaria Estadual de Educação de Minas Gerais e concluiu-se que o caráter impositivo na implantação do Programa ocasionou um distanciamento entre a política pública e as reais demandas das instituições de ensino e educadores da rede estadual, levando ao não uso efetivo das TIC pelos professores formados. Esses registros são importantes, uma vez que a incorporação de tecnologias na prática docente é o objetivo, ainda que implícito, de todas as ações de formação continuada que visam promover o uso pedagógico das TIC. Apesar disso, resultados que discorrem acerca desse objetivo foram encontrados em apenas nove artigos.

A categoria Reflexão sobre o uso das TIC enfatiza as ações que explicitamente indicaram que as atividades formativas oportunizaram processos de reflexão sobre a prática docente com o uso das TIC, elemento descrito em sete artigos. Os processos reflexivos foram propiciados de diferentes formas, como em espaço virtual de aprendizagem (A8 e A28), através de discussões presenciais (A2 e A25) e a partir de questões orientadoras e registros escritos (A9).

A reflexão é tida como um importante elemento de formação, uma vez que é um instrumento de desenvolvimento do pensamento, da ação e de desenvolvimento profissional. Através de movimentos reflexivos, o docente pode construir conhecimentos a partir de sua experiência e de saberes que o levam à compreensão e (re)organização de ideias que articulem teoria e prática (Micheletto \& Levandovski, 2013). Sem a reflexão acerca do processo educativo, as práticas docentes tendem a se tornar repetitivas e acríticas, isso porque, segundo Schön (2000), quando se aprende a fazer algo, realiza-se a tarefa de maneira mecânica, sem pensar muito a respeito. Por outro lado, um professor que realiza o exercício reflexivo da sua prática docente se torna um investigador das suas ações pedagógicas, tendo condições de avaliar os processos de ensinoaprendizagem e implementar mudanças, sempre que necessário.

Três artigos apresentaram como resultados de formação os Significados atribuídos por professores a temáticas relacionadas às ações de formação. Em A21 foram registrados, em diferentes momentos da formação do Programa Nacional de Formação Continuada em Tecnologia Educacional (ProInfo Integrado), os tipos e articulação entre os discursos envolvendo letramentos e tecnologias. Em uma formação continuada em conexões interculturais (A10), foram investigados os sentidos atribuídos por professores a tecnologias e educação. Já em um curso de "Formação do Professor para o Ensino/Aprendizagem de Línguas Estrangeiras em Tandem' (A29), foi realizado um levantamento sobre as concepções dos professores sobre cultura.

Houve o registro de Construção de conhecimentos disciplinares em dois trabalhos, categoria que reúne os resultados de ações de formação que focaram no desenvolvimento de conteúdos específicos de uma área de conhecimento. A ação de formação analisada em A12 evidenciou a ampliação do arcabouço linguístico referente à Língua Portuguesa e à Libras dos cursistas. Já em A23 foi identificada a apropriação de temas matemáticos (paralelismo, proporcionalidade, semelhança e homotetia) pelos professores.

A categoria Aprendizagem dos alunos salienta resultados de formação que revelam ganhos ao desempenho escolar e à aquisição de conhecimento pelos discentes dos professores que participaram de ações de formação, algo explicitado em dois artigos. O trabalho A19 evidenciou que as ações pedagógicas desenvolvidas por professores que participaram do "Curso de Formação do ProuUCA - Tocantins" impulsionaram "a fluência da leitura entre os estudantes; o compartilhamento de informações, a colaboração na interpretação das ideias; e a coautoria na 
elaboração dos diálogos das HQs" (p. 415). Já os professores participantes da Especialização do "Programa de Formação Continuada Mídias na Educação", contexto investigado em A14, afirmaram que a inserção das TIC nas suas práticas pedagógicas possibilitou a participação mais ativa e o desenvolvimento de autonomia pelos alunos, a contextualização de conhecimentos e a aquisição de conhecimentos e habilidades necessárias à inserção no mercado de trabalho. A aprendizagem dos alunos é uma forma de avaliação muito utilizada quando os programas de formação não avaliam os professores após sua participação em atividades de formação continuada (Davis et al., 2012). Este não foi o caso dos trabalhos analisados no presente trabalho, pois ele foi encontrado em apenas dois artigos que não abordaram unicamente esse aspecto como resultado de formação.

O Interesse em utilizar as TIC futuramente é uma categoria que indica que as ações de formação promoveram entusiasmo nos professores para uso de TIC na sua prática docente. Ela foi registrada em um artigo, o A2, que indicou o interesse dos professores participantes da "Oficina sobre a metodologia WebQuest para o ensino da matemática" em usarem WebQuests na sua prática docente. A motivação para uso de TIC é um importante elemento na concretização desse uso, embora ela sozinha não garanta que isso ocorra.

\section{Considerações Finais}

Este trabalho visou construir um panorama acerca das ações de formação continuada docente no Brasil que promovem o uso pedagógico das TIC, considerando as características das ações, do perfil do público-alvo e do mapeamento dos resultados formativos. A partir dos resultados, observa-se que essas ações de formação se utilizam, em sua maioria, de elementos do ensino a distância e centram-se em professores da educação básica pública, sendo os professores de matemática especialmente atendidos. A análise dos resultados de formação indicou que as ações contribuíram para o estabelecimento de redes de relacionamento entre os docentes; a construção de conhecimentos e a revelação de significados sobre as TIC; a utilização, reflexão sobre o uso e desenvolvimento de interesse na utilização das TIC; a formação de conhecimentos disciplinares; e a aprendizagem dos alunos.

Sobre esse panorama, chama a atenção o fato de que mais de $60 \%$ das ações investigadas terem sido ofertadas através da EaD. Barbosa e Ursi (2019) mostram que, apesar de os professores considerarem a EaD uma modalidade de ensino motivadora, por, principalmente, permitir uma flexibilidade na gestão do seu tempo, ela apresenta a desvantagem de prescindir de interação presencial. A maioria das ações a distância aqui analisadas foram realizadas de modo semipresencial, formato que agrega a flexibilidade temporal e possibilidade de contato presencial entre cursistas, professores e tutores. Esses aspectos podem minimizar a evasão dos cursos de formação continuada (Barbosa \& Ursi, 2019).

Outro ponto que deve ser evidenciado é que grande parte dos resultados de formação estão atrelados não somente à utilização, à construção de saberes e à reflexão sobre às TIC, mas também ao desenvolvimento de outros aspectos da vida docente, como a formação de redes de relacionamento, a construção de conhecimentos disciplinares e a aprendizagem dos alunos. Isso é positivo, já que a utilização de inovações didáticas por professores resulta da combinação de diferentes fatores, que vão além do conhecimento sobre as TIC em si. Alguns fatores intimamente relacionados aos resultados formativos citados são a influência e colaboração dos colegas, conhecimento sobre como integrar as TIC às atividades de ensino e a preocupação com a aprendizagem dos estudantes (Espíndola, Struchiner, \& Giannella, 2010).

O retrato apresentado, ao mesmo tempo que ilustra o que as ações de formação são e como elas têm colaborado para o desenvolvimento profissional docente, também revela os seus limites. Se faz necessário ampliar a oferta da formação continuada para atender professores das mais 
variadas disciplinas e níveis de ensino. Destacou-se também o fato de que poucos trabalhos investigaram ações atreladas às políticas governamentais de formação continuada docente para uso pedagógico das TIC.

Davis e colaboradores (2012) refletem que ações de desenvolvimento profissional que são isoladas e não articuladas a um empreendimento maior podem carecer de coerência interna (entre objetivos, métodos e resultados) e de coerência sistêmica entre as demais políticas voltadas para a formação de professores (aspectos da carreira docente, salários, entre outros). Além disso, a BNC-Formação Continuada defende que é necessário que haja uma coerência das ações de formação com os currículos, os Projetos Políticos Pedagógicos (PPP) das escolas, os materiais de suporte pedagógico e o sistema de avaliação, ou seja, a elementos pertencentes ao "chão da escola" (Brasil, 2020). Isso foi pouco evidenciado nas ações formativas aqui analisadas, uma vez que elas se mostraram, de maneira geral, focadas no professor (individualizada) e não no corpo de professores de uma mesma instituição (colaborativa). $\mathrm{O}$ aspecto negativo dessa característica é que pode haver um esvaziamento das metas formativas quando as ações de formação não asseguram que os professores, em seu ambiente de trabalho, tenham com quem discutir as aprendizagens e reflexões realizadas (Davis et al., 2012). É importante lembrar que foi resultado de muitas ações o estabelecimento de redes de relacionamento entre os docentes e a promoção da reflexão sobre o uso das TIC, mas como as formações geralmente não focaram em grupos de professores de uma mesma instituição de ensino a análise aqui realizada não indica que os preceitos estabelecidos na BNC-Formação Continuada estejam sendo realizados.

Por fim, é pertinente ressaltar que o retrato das ações de formação continuada docente para o uso das TIC aqui consolidado é fruto de uma visão delimitada sobre a temática, posto que as decisões metodológicas tomadas pelos autores, notadamente as concernentes ao processo de busca de trabalhos, emprego dos critérios de exclusão e tipos de documentos consultados restringiram o acesso aos possíveis dados. Tais procedimentos metodológicos, contudo, certamente propiciaram robustez à análise, já que os métodos utilizados visaram a seleção criteriosa dos estudos. Outra limitação do estudo é que o panorama aqui apresentado provavelmente sofreu transformações devido à pandemia da COVID-19, que provocou mudanças na educação nacional, levando à suspensão das aulas presenciais no Brasil e ao oferecimento de atividades pedagógicas remotas. Esse fato impulsionou a oferta de ações de formação continuada docente visando o uso das TIC de uma forma nunca antes vista no cenário educacional brasileiro.

\section{Referências}

Almeida, M. E. B., \& Valente, J. A. (2016). Políticas de Tecnologia na Educação Brasileira: histórico, lições aprendidas e recomendações. São Paulo, SP: Centro de Inovação para a Educação Brasileira. Disponível em: https://cieb.net.br/wp-content/uploads/2019/04/CIEBEstudos-4-Politicas-de-Tecnologia-na-Educacao-Brasileira-v.-22dez2016.pdf [GS Search]

Atanazio, A. M. C., \& Leite, A. E. (2018). Tecnologias da Informação e Comunicação (TIC) e a formação de professores: tendências de pesquisa. Investigações em Ensino de Ciências, 23 (2), 88-103. doi: 10.22600/1518-8795.ienci2018v23n2p88 [GS Search]

Bahia, N. P. (2014). A formação inicial de professores a distância, que tanto incomoda! Educação \& Linguagem, 17 (2), 121-143. doi: 10.15603/2176-1043/el.v17n2p121-143 [GS Search]

Barbosa, P. P., \& Ursi, S. (2019). Motivação para formação continuada em Educação a Distância: um estudo exploratório com professores de Biologia. Revista Electrónica de Enseñanza de las Ciencias, 18 (1), 148-172. Disponível em: http://revistas.educacioneditora.net/index.php/REEC/article/view/367/36 [GS Search] 
Baptista, M. (2014). Researching Practice and Collaboration as a Means to Promote Inquiry in Science Teaching. Problems of Education in the 21st Century, 59, 5-6. Disponível em: http://oaji.net/articles/2014/457-1420361699.pdf [GS Search]

Bardin, L. (2016). Análise de Conteúdo. São Paulo: Edições70. [GS Search]

Barreto, R. G., Guimarães, G. C., Magalhães, L. K. C., \& Leher, E. M. T. (2006). As tecnologias da informação e da comunicação na formação de professores. Revista Brasileira de Educação, 11 (31), 31-42. doi: 10.1590/S1413-24782006000100004 [GS Search]

Bingimlas, K. A. (2009). Barriers to the Successful Integration of ICT in Teaching and Learning Environments: A Review of the Literature. Eurasia Journal of Mathematics, Science \& Technology Education, 5 (3), 235-245. doi: 10.12973/ejmste/75275 [GS Search]

Brasil. (1997). Parâmetros curriculares nacionais: introdução aos parâmetros curriculares nacionais. Brasília, DF: MEC/SEF. Disponível em: http://portal.mec.gov.br/seb/arquivos/pdf/livro01.pdf.

Brasil. (2013) Diretrizes Curriculares Nacionais Gerais da Educação Básica. Brasília, DF: MEC/SEB. Disponível

em: http://portal.mec.gov.br/index.php?option=com docman\&view=download\&alias=13448diretrizes-curiculares-nacionais-2013-pdf\&Itemid=30192.

Brasil. (2015). Conselho Nacional de Educação. Resolução CNE/CP Nº 2, de 1 de julho de 2015. Define as Diretrizes Curriculares Nacionais para a formação inicial em nível superior (cursos de licenciatura, cursos de formação pedagógica para graduados e cursos de segunda licenciatura) e para a formação continuada. Disponível em: http://portal.mec.gov.br/docman/agosto-2017-pdf/70431-res-cne-cp-002-03072015-pdf/file

Brasil (2018). Base Nacional Comum Curricular. Brasília, DF: MEC. Disponível em: http://basenacionalcomum.mec.gov.br/images/BNCC EI EF 110518 versaofinal site.pdf

Brasil. (2020). Conselho Nacional de Educação. Resolução CNE/CP N ${ }^{\circ}$, de 27 de outubro de 2020. Dispõe sobre as Diretrizes Curriculares Nacionais para a Formação Continuada de Professores da Educação Básica e institui a Base Nacional Comum para a Formação Continuada de Professores da Educação Básica (BNC-Formação Continuada). Disponível em: http://portal.mec.gov.br/docman/outubro-2020-pdf/164841-rcp001-20/file

Casquero, G. B., García, L. M. C., \& González, R. L. (2011). Obstáculos percibidos para la integración de las tic por los profesores de infantil y primaria en extremadura. Revista de Medios y Educación, 39, 83-94. Disponível em: https://www.redalyc.org/articulo.oa?id=36818685008 [GS Search]

Costa, C., \& Ferreira, R. (2020). Revisão Sistemática sobre Letramento Digital na Formação de Professores: desafios e possibilidades. In Anais do XXXI Simpósio Brasileiro de Informática na Educação, (pp. 282-291). Porto Alegre: SBC. doi:10.5753/cbie.sbie.2020.282 [GS $\underline{\text { Search] }}$

Critical Appraisal Skills Programme (2018). CASP Qualitative Studies Checklist. Disponível em: https://casp-uk.net/wp-content/uploads/2018/03/CASP-Qualitative-Checklist2018 fillable form.pdf.

Davis, C. L. F, Nunes, M. M. R., Almeida, P. C. A., Silva, A. P. F., \& Souza, J. C. (2012). Formação continuada de professores: Uma análise das modalidades e das práticas em estados e municípios brasileiros. São Paulo, SP: FCC/DPE. Disponível em: http://publicacoes.fcc.org.br/index.php/textosfcc/article/view/2452/2407 [GS Search] 
Dorigoni, G. M. L., \& Silva, J. C. (2013). Mídia e Educação: o uso das novas tecnologias no espaço escolar.

Disponível: http://www.gestaoescolar.diaadia.pr.gov.br/arquivos/File/producoes_pde/artigo_gilza_mari a_leite_dorigoni.pdf. [GS Search]

Dorneles, D. M. (2012). A formação do professor para o uso das tics em sala de aula: uma discussão a partir do projeto piloto UCA no Acre. Texto Livre: Linguagem e Tecnologia, 5 (2), 71-87. doi: 10.17851/1983-3652.5.2.71-87 [GS Search]

Estevam, E. R., \& Sales, S. R. (2018). Formação de professores e tecnologias digitais: levantamento e análise da produção discente na pós-graduação em educação. Revista Intersaberes, 13 (18), 37-50. doi: 10.22169/revint.v13i28.1360 [GS Search]

Espíndola, M. B.; Struchiner, M.; Giannella, T. R. (2010). Integração de Tecnologias de Informação e Comunicação no Ensino: Contribuições dos Modelos de Difusão e Adoção de Inovações para o campo da Tecnologia Educacional. Revista Latinoamericana de Tecnología Educativa RELATEC, 9 (1), 89-106. Disponível em: http://campusvirtual.unex.es/revistas/index.php/relatec/article/viewFile/612/444 [GS Search]

Faria, A. A., \& Lopes, L. F. (2013). O que e o quem da Ead: história e fundamentos. Curitiba: Intersaberes. [GS Search]

Gatti, B. (2008). Análise das políticas públicas para formação continuada no Brasil, na última década. Revista Brasileira de Educação, 13, 37, 57-70. doi: 10.1590/S1413$\underline{24782008000100006}$ [GS Search]

Gewehr, D. (2016). Tecnologias Digitais de Informação e Comunicação (TDICSs) na escola e em ambientes não escolares. 136 f. Dissertação (Mestrado em Ensino). Centro Universitário UNIVATES, Lajeado, RS. [GS Search]

Gonçalves, H. A., Nascimento, M. B. C., \& Nascimento, K. C. S. (2015). Revisão sistemática e metanálise: níveis de evidência e validade científica. Revista Eletrônica Debates em Educação Científica e Tecnológica, 5 (3), 193-211. doi: 10.36524/dect.v5i03.129 [GS Search]

Galvão, C. M., Sawada N. O., \& Trevizan M. A. (2004). Revisão sistemática: recurso que proporciona a incorporação das evidências na prática da enfermagem. Revista Latinoamericana de Enfermagem, 12 (3), 549-56. doi: 10.1590/S0104-11692004000300014 [GS $\underline{\text { Search] }}$

Kenski, V. M. (2001). Em direção a uma ação docente mediada pelas tecnologias digitais. In R. G. Barreto (Org.). Tecnologias educacionais e educação a distância: avaliando políticas e práticas. (pp. 74-84). Rio de Janeiro, RJ: Quartet. [GS Search]

Mamede-Neves, M. A. C. (1996). Aprendizagem por identificação. Rio de Janeiro, RJ: CEPERJ. [GS Search]

Martins, Z. (2009). As TIC no ensino-aprendizagem da matemática. In Actas do X Congresso Internacional Galego-português de Psicopedagogia. Braga: Universidade do Minho. Disponível

em: https://www.educacion.udc.es/grupos/gipdae/documentos/congreso/Xcongreso/pdfs/t7/t7c2 00.pdf [GS Search]

Martins, R. X., \& Flores, V. F. (2015). A implantação do Programa Nacional de Tecnologia Educacional (ProInfo): revelação de pesquisas realizadas no Brasil entre 2007 e 2011. Revista Brasileira de Estudos Pedagógicos (online), 96 (242), 112-128. doi: 10.1590/S2176$\underline{6681 / 330812273}$ [GS Search] 
Matos, N. C., Souza, E. R., Nascimento, J. V., Pinto, M. G., \& Souza, A. R. B. (2016). A formação continuada de professores da educação básica: uma revisão sistemática. Cadernos de pesquisa: Pensamento Educacional, 11 (28), 45-64. Disponível em: https://interin.utp.br/index.php/a/article/view/311/312 [GS Search]

Micheletto, I. B. P., \& Levandovski, A. R. (2013). Ação-reflexão-ação: processo de formação continuada. 2013. Disponível em: http://www.diaadiaeducacao.pr.gov.br/portals/pde/ arquivos/1448-6.pdf [GS Search]

Mill, D. (2013). Análise da educação a distância como interseção entre a formação docente, as tecnologias digitais e a pós-graduação. Educação em Perspectiva, 4 (2), 343-369. doi: 10.22294/eduper/ppge/ufv.v4i2.413 [GS Search]

Miskulin, R. G. S., Perez, G., Silva, M. R. C., Montrezor, C., Santos, C., Toon, E., Liboni-Filho, P., \& Santana, P. H. (2006). Identificação e análise das dimensões que permeiam a utilização das tecnologias de informação e comunicação nas aulas de matemática no contexto da formação de professores. Bolema, 19 (26), 1-16. Disponível em: https://www.periodicos.rc.biblioteca.unesp.br/index.php/bolema/article/view/1869 [GS Search]

Moura, K. M. P. (2019). Revisão sistemática sobre letramento digital na formação de professores. Texto livre: linguagem e tecnologia, 12 (3), 128-143. doi: 10.17851/1983-3652.12.3.128-143 [GS Search]

Nogueira, F., Pessoa, T., \& Gallego, M. J. (2015). Desafios e oportunidades do uso da tecnologia para a formação contínua de professores: uma revisão em torno do TPACK em Portugal, Brasil e Espanha. Tear: Revista de Educação, Ciência e Tecnologia, 4 (2), 1-20. Disponível em: $\quad$ https://www.researchgate.net/profile/Maria_Jesus_GallegoArrufat/publication/286256046_Desafios_e_oportunidades_do_uso_da_tecnologia_para_a formacao_continua_de_professores_uma_revisao_em_torno_do_TPACK_em_Portugal_Br asil_e_Espanha/links/5667379d08ae34c89a0237a1/Desafios-e-oportunidades-do-uso-datecnologia-para-a-formacao-continua-de-professores-uma-revisao-em-torno-do-TPACKem-Portugal-Brasil-e-Espanha.pdf [GS Search]

Oliveira, A. M. G., \& Lima, G. S. N. (2015). A gestão educacional e a efetivação de políticas públicas para utilização das TIC na educação. Revista Exitus, 5, 2, 125-137. Disponível em: http://www.ufopa.edu.br/portaldeperiodicos/index.php/revistaexitus/article/view/66/66 [GS $\underline{\text { Search] }}$

Oliveira, T. A. L., Delamuta, B. H., Silveira, M. P., \& Mól, G. S. (2018). Formação Continuada de professores de Química para o uso das Tecnologias: uma Revisão Sistemática de Literatura. Revista Valore, 3 (edição especial), 1-13. Disponível em: https://revistavalore.emnuvens.com.br/valore/article/view/131/124 [GS Search]

Pedro, N., \& Piedade, J. (2013). Efeitos da formação na autoeficácia e na utilização educativa das TIC pelos professores: estudo das diferenças entre regimes formais e informais de formação. Revista e-Curriculum, 11 (3), 766-793. Disponível em: https://revistas.pucsp.br/index.php/curriculum/article/view/9002/13300 [GS Search]

Pedrosa, S. A educação a distância na formação continuada do professor. (2003). Educar em Revista, 21, 1-15. doi: 10.1590/0104-4060.283 [GS Search]

Peralta, H., \& Costa, F. A. (2007). Competência e confiança dos professores no uso das TIC: Síntese de um estudo internacional. Revista de Ciências da Educação, 3, 77-86. Disponível em:

http://www.letstryict.eu/press/Costa F Compet ncia e confian a dos professores no uso das TIC $\underline{\text { S_ntese de um estudo_internacional }}$ S S sifo _ N 3 2007.pdf [GS Search] 
Pretto, N., \& Riccio, N. (2010). A formação continuada de professores universitários e as tecnologias digitais. Educar em Revista, 37, 153-169. doi: 10.1590/S010440602010000200010 [GS Search]

Romanowski, J. (2013). Tendências da pesquisa em formação de professores. Atos de Pesquisa em Educação, 8 (2), 479-499. doi: 10.7867/1809-0354.2013v8n2p479-499 [GS Search]

Schön, D. A. (2000). Educando o profissional reflexivo: um novo design para o ensino e a aprendizagem. Porto Alegre, RS: Artmed. [GS Search]

Schuhmacher, V. R. N., Alves-Filho, J. P., \& Schuhmacher, E. (2017). As barreiras da prática docente no uso das tecnologias de informação e comunicação. Ciência e Educação, 23 (3), 563-576. doi: 10.1590/1516-731320170030002 [GS Search]

Silva, H., Jambeiro, O., Lima, J., \& Brandão, M. (2005). Inclusão digital e educação para a competência informacional: uma questão de ética e cidadania. Ciência da Informação [online], 34 (1), 28-36, 2005. doi: 10.1590/S0100-19652005000100004 [GS Search]

Silva, I. C. S., Prates, T. S., \& Ribeiro, L. F. S. (2016). As Novas Tecnologias e aprendizagem: desafios enfrentados pelo professor na sala de aula. Revista Em Debate, 16, 107-123. doi: $\underline{10.5007 / 1980-3532.2016 n 15 p 107}$ [GS Search]

Soares-Leite, W. S., \& Nascimento-Ribeiro, C. A. (2012). A inclusão das TICs na educação brasileira: problemas e desafios. Magis, 5 (10), 173-187. Disponível em: https://dialnet.unirioja.es/servlet/articulo?codigo=4434902 [GS Search]

Souza, A. A. N., \& Schneider, H. N. (2016). Tecnologias digitais na formação inicial docente: articulações e reflexões com uso de redes sociais. Educação Temática e Digital, 18 (2), 418436. doi:10.20396/etd.v18i2.8640946 [GS Search]

Spagnolo, C., Mantovani, A. M., Santos, B. S., \& Müller, C. A. (2014). As tecnologias da informação e da comunicação como mediadoras no processo de formação docente: um recorte nos grupos de trabalho da ANPED - 2009 a 2012. Revista Reflexão e Ação, 22 (1), 203-222. doi: 10.17058/rea.v22i1.3852 [GS Search]

Takahashi, T. (2000). Sociedade da informação no Brasil: livro verde. Brasília, DF: Ministério da Ciência e Tecnologia. [GS Search] 


\section{Apêndice}

\begin{tabular}{|c|c|c|}
\hline Código & Autores & Título do artigo \\
\hline A1 & Abar \& Alencar (2013) & $\begin{array}{l}\text { A Gênese Instrumental na Interação com o GeoGebra: uma proposta para a formação continuada } \\
\text { de professores de Matemática }\end{array}$ \\
\hline A2 & $\begin{array}{l}\text { Azevedo, Puggian, \& Friedmann } \\
\text { (2013) }\end{array}$ & $\begin{array}{l}\text { WebQuests, Oficinas e Guia de Orientação: uma proposta integrada para a formação continuada } \\
\text { de professores de matemática }\end{array}$ \\
\hline A3 & $\begin{array}{l}\text { Azevedo, Puggian, \& Friedmann } \\
\text { (2017) }\end{array}$ & Webquest fácil: um site para o ensino de matemática \\
\hline A4 & $\begin{array}{l}\text { Barcelos, Passerino, \& Behar } \\
(2011)\end{array}$ & $\begin{array}{l}\text { Redes sociais na internet: ambiente pessoal de aprendizagem na formação de professores } \\
\text { iniciantes de matemática }\end{array}$ \\
\hline A5 & Barcelos (2012) & Redes sociais e formação de professores \\
\hline A6 & $\begin{array}{l}\text { Barcelos, Passerino, \& Behar } \\
(2012)\end{array}$ & Rede social na internet: apoio para formação continuada de professores de matemática \\
\hline A7 & $\begin{array}{l}\text { Barcelos, Passerino, \& Behar } \\
(2013)\end{array}$ & $\begin{array}{l}\text { Formação continuada com apoio de uma rede social na internet: Tecnologias na Prática Docente } \\
\text { de Professores de Matemática }\end{array}$ \\
\hline A8 & $\begin{array}{l}\text { Bardy, Hayashi, Schlünzen, \& } \\
\text { Seabra Júnior (2013) }\end{array}$ & $\begin{array}{l}\text { Objetos de aprendizagem como recurso pedagógico em contextos inclusivos: subsídios para A } \\
\text { formação de professores A distância }\end{array}$ \\
\hline A9 & Bassani \& Eltz (2018) & $\begin{array}{l}\text { Autoria docente na web: produção e compartilhamento de registros reflexivos sobre práticas } \\
\text { pedagógicas com tecnologias digitais }\end{array}$ \\
\hline A10 & Bueno, Paniago, \& Santos (2014) & $\begin{array}{l}\text { Formação continuada de professores em conexões interculturais no facebook: pluralidade de } \\
\text { sentidos e significados sobre tecnologias e educação }\end{array}$ \\
\hline A11 & $\begin{array}{l}\text { Chagas, Demoly, Rebouças, \& } \\
\text { Gonçalves (2014) }\end{array}$ & Atuação docente na inter-relação dos letramentos alfabético e digital no ciberespaço \\
\hline A12 & $\begin{array}{l}\text { Corrêa, Vieira, Santarosa, \& Biasuz } \\
\text { (2014) }\end{array}$ & $\begin{array}{l}\text { Tecnologia Assistiva: a inserção de aplicativos de tradução na promoção de uma melhor } \\
\text { comunicação entre surdos e ouvintes }\end{array}$ \\
\hline A13 & Costa (2008) & $\begin{array}{l}\text { Mudanças da cultura docente em um contexto de trabalho colaborativo mediado pelas } \\
\text { tecnologias de informação e comunicação }\end{array}$ \\
\hline A14 & Couto \& Rezende-Filho (2013) & $\begin{array}{l}\text { Mídias na Educação: Discurso Oficial nos Discursos de Professores Egressos de um Programa } \\
\text { de Formação Continuada }\end{array}$ \\
\hline A15 & Cyrino \& Baldini (2017) & $\begin{array}{l}\text { Ações da formadora e a dinâmica de uma comunidade de prática na constituição/mobilização } \\
\text { de TPACK }\end{array}$ \\
\hline A16 & Estabel, Moro, \& Santarosa (2009) & $\begin{array}{l}\text { A formação de professores e a capacitação de bibliotecários com limitação visual por meio da } \\
\text { EAD em ambiente virtual de aprendizagem }\end{array}$ \\
\hline A17 & $\begin{array}{l}\text { Garbin, Garcia, Amaral, \& Silva } \\
\text { (2014) }\end{array}$ & A colaboração na formação continuada de professores: o projeto m-learning \\
\hline A18 & $\begin{array}{l}\text { Heckler, Motta, Dorneles, \& } \\
\text { Galiazzi (2014) }\end{array}$ & Uma proposição metodológica para compreender a experimentação em ciências na EAD \\
\hline A19 & Lemos (2016) & $\begin{array}{l}\text { Profissionalização docente nas escolas públicas do estado de Tocantins: novo contexto de ensino } \\
\text { e aprendizagem pelas tecnologias digitais }\end{array}$ \\
\hline A 20 & Marson \& Santos (2008) & $\begin{array}{l}\text { Podcast, Audacity, Youtube, Skypecast, Chat e Webquest: Possibilidades didáctico-pedagógicas } \\
\text { na Internet para o docente de língua inglesa }\end{array}$ \\
\hline $\mathrm{A} 21$ & Miranda (2014) & $\begin{array}{l}\text { Integração das tecnologias digitais da informação e comunicação em contextos educacionais: } \\
\text { análise de três momentos de um curso oficial de formação de professores }\end{array}$ \\
\hline A 22 & Oliveira, Rego, \& Villardi (2007) & $\begin{array}{l}\text { Aprendizagem mediada por ferramentas de interação: análise do discurso de professores em um } \\
\text { curso de formação continuada a distância }\end{array}$ \\
\hline A23 & Oliveira \& Lima (2018) & $\begin{array}{l}\text { Estratégias didáticas com tecnologias na formação continuada de professores de Matemática: } \\
\text { uma investigação sobre homotetia }\end{array}$ \\
\hline A24 & Orth, Fuet, Otte, \& Neves (2013) & $\begin{array}{l}\text { Ambientes virtuais de aprendizagem e formação continuada de professores na modalidade a } \\
\text { distância }\end{array}$ \\
\hline
\end{tabular}




\begin{tabular}{|l|l|l|}
\hline A25 & Pagnez (2006) & $\begin{array}{l}\text { Projeto Eureka: A implantação da informática educativa na rede municipal de Campinas no } \\
\text { período de 1989-1997 }\end{array}$ \\
\hline A26 & Prado \& Lobo da Costa (2016) & $\begin{array}{l}\text { O papel da atividade de programação no processo de construção de conhecimentos para a } \\
\text { docência }\end{array}$ \\
\hline A27 & $\begin{array}{l}\text { Rocha, Dorneles, \& Marranghello } \\
\text { (2012) }\end{array}$ & $\begin{array}{l}\text { Reflexões sobre o processo de formação continuada proposto por um curso de especialização } \\
\text { em Educação em Ciências e Tecnologia }\end{array}$ \\
\hline A28 & Rodrigues \& Stano (2016) & $\begin{array}{l}\text { A formaçao docente como construção coletiva de conhecimentos em uma experiência de web } \\
\text { currículo }\end{array}$ \\
\hline A29 & Salomão (2017) & Concepções de cultura no ensino de línguas: reflexões para a formação professores \\
\hline A31 & Silva \& Garíglio (2010) & $\begin{array}{l}\text { A formação continuada de professores para o uso das Tecnologias da Informação e } \\
\text { Comunicação (TIC): o caso do projeto Escolas em Rede, da Rede Estadual de Educação de } \\
\text { Minas Gerais }\end{array}$ \\
\hline A32 & Vetromille-Castro (2008) & Dialogando sobre e Planejando com o SuperLogo no Ensino de Matemática dos Anos Iniciais \\
\hline
\end{tabular}

